\title{
An RNA enhancer in a phage transcriptional antitermination complex functions as a structural switch
}

\author{
Leila Su, ${ }^{1,4}$ James T. Radek, ${ }^{1,4}$ Laura A. Labeots, ${ }^{1}$ Klaas Hallenga, ${ }^{1}$ Patrick Hermanto, ${ }^{1}$ \\ Huifen Chen, ${ }^{1}$ Satoe Nakagawa, ${ }^{1}$ Ming Zhao, ${ }^{1}$ Steve Kates, ${ }^{2}$ and Michad A. Weiss ${ }^{1,3,5}$ \\ ${ }^{1}$ Department of Biochemistry and Molecular Biology and Center for Molecular Oncology, The University of Chicago, \\ Chicago, Illinois 60637-5419 USA; ${ }^{2}$ PerSeptive Biosystems, Framingham, M assachusetts 01710 USA; ${ }^{3}$ Department of \\ Chemistry, The University of Chicago, Chicago, Illinois 60637 USA
}

\begin{abstract}
Antitermination protein $\mathrm{N}$ regulates the transcriptional program of phage $\lambda$ through recognition of RNA enhancer elements. Binding of an arginine-rich peptide to one face of an RNA hairpin organizes the other, which in turm binds to the host antitermination complex. The induced RNA structure mimics a GNRA hairpin, an organizational element of rRNA and ribozymes. The two faces of the RNA, bridged by a sheared GA base pair, exhibit a specific pattem of base stacking and base flipping. This pattem is extended by stacking of an aromatic amino acid side chain with an unpaired adenine at the $\mathrm{N}$-binding surface. Such extended stacking is coupled to induction of a specific internal RNA architecture and is blocked by RNA mutations associated in vivo with loss of transcriptional antitermination activity. Mimicry of a motif of RNA assembly by an RNA-protein complex permits its engagement within the antitemination machinery.
\end{abstract}

[Key Words: Gene regulation; transcriptional elongation; nut site; RN A structure; RNA polymerase]

Received February 7, 1997; revised version accepted July 15, 1997.

A general feature of protein-RNA recognition is costabilization of novel binding surfaces (Tan and Frankel 1995). The structural diversity of RN A - a rich repertoire of nonstandard base pai ring and backbone organizationunderlies its biological role in macromolecular assembly and catalysis (Cate et al. 1996). Protein binding is often accompanied by large-scal e rearrangement of RN A structure; examples are provided by the Tat and Rev proteins of mammalian immunodeficiency viruses (Puglisi et al. 1993, 1995; Battiste et al. 1994, 1996; Ye et al. 1995). Induced RN A structures exhibit nonstandard base pairing and stacking in association with changes in the dimension of grooves. Are such features an epiphenomenon of recognition or of broader biological importance? In particular, does the diverse structural repertoire of RNA make possible novel mechanisms of gene regulation? To address these questions, we have investigated the RNA-based control of a viral developmental program.

Phage $\lambda$ provides a model of antitermination in the positive control of transcription (Roberts 1969; Salstrom and Szybalski 1978; Franklin 1985ab). Expression of delayed-early genes requires that RNA polymerase read through Rho-dependent and intrinsic terminators (for re-

\footnotetext{
${ }^{4}$ These authors contributed equally to this work.

${ }^{5}$ Corresponding author.

E-MAIL maweiss@midway.uchicago.edu; FAX (773) 702-4394.
}

view, see Das 1993; Greenblatt et al. 1993). Antitermination is directed by the $\lambda \mathrm{N}$ protein in concert with host factors N usA, N usB, N usG, and S10 (Fig. 1A; Schauer et al. 1987; Whalen et al . 1988; M ason and Greenblatt 1991; Li et al. 1992; Mason et al. 1992; DeVito and Das 1994). $\mathrm{N}$ activity at physiological concentrations is directed by RNA enhancer elements ( $\lambda N$-utilization sites; nutL and nutR) upstream in the nascent message (de $C$ rombrugghe et al. 1979; Olson et al. 1982; Barik et al. 1987; Whalen and Das 1990; Patterson et al. 1994). A nut site consists of a 5'-single-stranded RNA element (boxA), a short single-stranded linker, and a $3^{\prime}$ hairpin (boxB). boxA, conserved among lamboid phages $\lambda$, P22, and $\phi 21$ (Friedman and Olson 1983; Olson et al. 1984; Nodwell and Greenblatt 1993), resembles antiterminator el ements in the RN A (rrn) operons of Escherichia coli (Li et al. 1984; M organ 1986; Albrechtsen et al. 1990). $\lambda$ boxA is inactive as an antitermination signal in the absence of boxB (Salstrom and Szybalski 1978), the site of N binding (Barik et al. 1987; Whal en and Das 1990). A mong lambdoid phages anal ogous boxB sites differ in sequence (Franklin 1985a), restricting the specificity of $\mathrm{N}$-dependent antitermination. Phage-specific boxB recognition by the $\lambda, P 22$, and \$21 N proteins (Franklin 1985b) is mediated by analogous arginine-rich motifs (Lazinski et al. 1989; Tan and Frankel 1995).

$\lambda$ boxB is a 15-base nonstandard RN A hairpin containing a purine-rich pental oop (Fig. 1B). The importance of $\mathrm{N}$-boxB recognition has been established by genetic and 

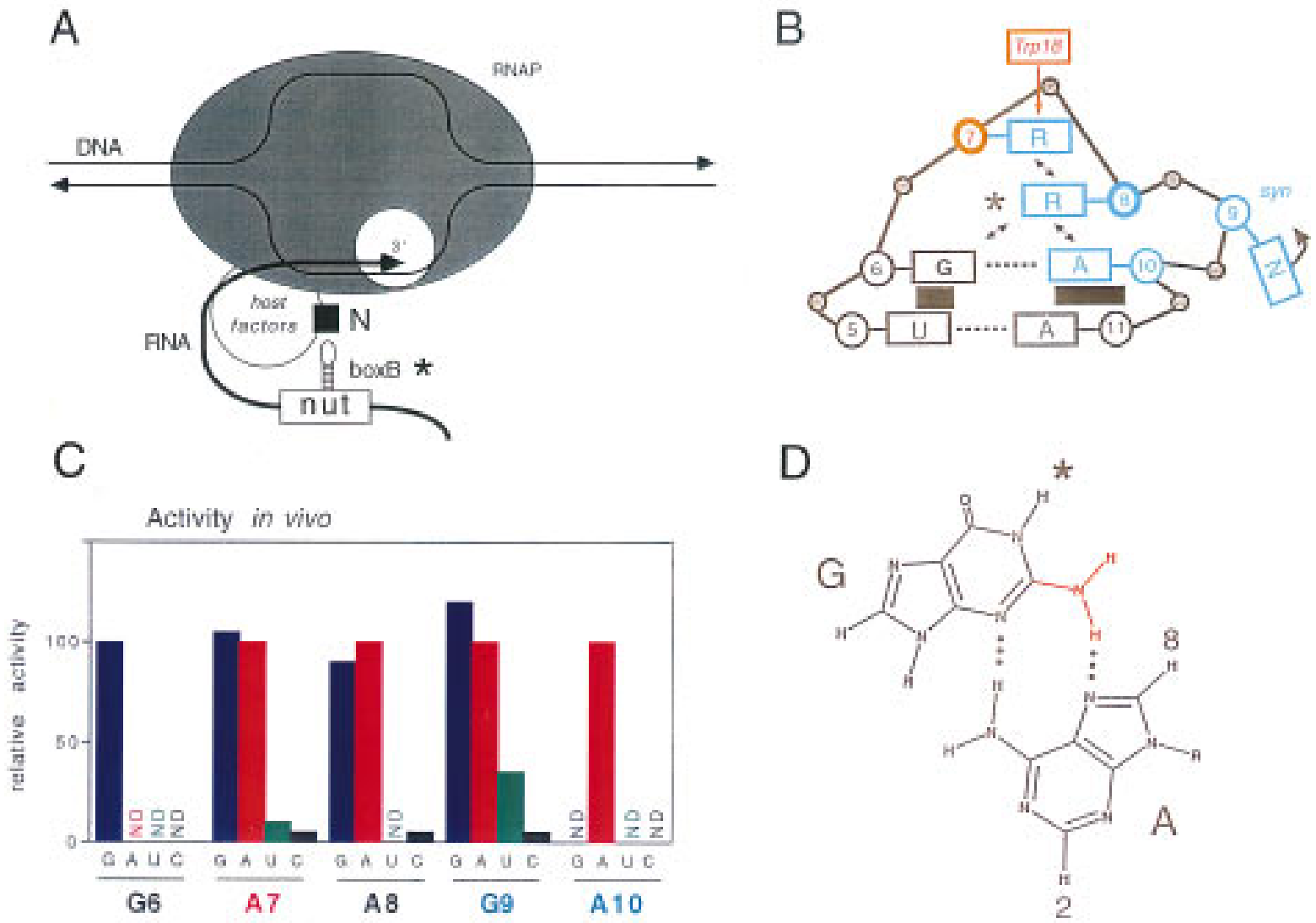

Figure 1. Overview of $\lambda \mathrm{N}$ regulatory system. (A) The $N$ protein binds to an RNA enhancer el ement in the nascent message (nut site; asterisk indicates boxB RN A hairpin) and to host factors and RN AP to direct formation of a processive antitermination complex. N ot shown: nut boxA RN A motif and interactions of the $\mathrm{N}$-nut complex with host $\mathrm{N}$ us elongation factors, including $\mathrm{N}$ usA. (B) $\mathrm{Closing}$ base pair (U5 and A 11) and purine-rich pental oop (bases 6-10; underlined) of 15-base nut ${ }_{L}$ boxB (5'-GCCCUGAAGAAGGGC-3'), with numbering scheme as shown. Red-outlined box (Trp-18) and nucleoside position (7) indicate site of indole-adenine stacking; blue nucleosides (7-10) exhibit a specific pattern of base-pairing (A10), -stacking (asterisk), and flipping (G9). Black rectangles indicate stacking between closing base pair (UA) and GA sheared base pair. Bidirectional arrows indicate N OEs between purines; base 9 is "flipped out." Peptide-RNA contacts (such as A7-Trp-18) were identified by isotope-filtered N M R experiments designed to resolve NOEs between ${ }^{13} \mathrm{C}$ - or ${ }^{15} \mathrm{~N}$-attached protons in a labeled peptide and ${ }^{12} \mathrm{C}$ - or ${ }^{14} \mathrm{~N}$-attached protons in the unlabeled RNA (Su et al. 1997). (C) Effects of base substitutions on the biological activity of the N-nut system in vivo (Doelling and Franklin 1989); analogous results have been obtained by Chattapadhyay et al. (1995a). One hundred percent is defined as the activity exhibited by the GAAAA loop. Bars are color-coded by base: dark blue $(G)$, red $(A)$, green $(U)$, and black $(C)$. (D) Structure of sheared GA base pair. The 2-amino group of guanine is shown in red; the asterisk indicates guanine imino proton (not involved in hydrogen bonding).

biochemical studies (Salstrom and Szybalski 1978; Nodwell and Greenblatt 1991; Franklin 1993; Chattopadhyay et al. 1995a; M ogridge et al. 1995). Evidence for an RNA signal in vivo has been provided by genetic analysis (Friedman and Olson 1983; Olson et al. 1984; Warren and Das 1984; Zuber et al. 1987); evidence in vitro has been provided by kinetic analysis of reconstituted transcription systems (Whalen and Das 1990). The $\mathrm{N}$-binding surface of boxB has been mapped by RN ase protection and mutagenesis; a second functional surface is recognized by NuSA in the assembly of a transcriptional antitermination complex (Chattopadhyay et al. 1995a; M ogridge et al. 1995). boxB thus provides a bi partite "RN A bridge" in a network of protein-protein and protein-RNA interactions.
In this paper we investigate a minimal model of the $\lambda$ $\mathrm{N}$ antitermination complex. We demonstrate that asymmetric binding of an arginine-rich peptide to one face of a flexible RNA hairpin leads to restructuring of the other. The $\mathrm{N}$ peptide stabilizes a specific pattern of basepairing, base-stacking, and base-flipping. This pattern resembles that of the classical GNRA tetraloop (Fig. 2A), an organizational motif of rRN A and catalytic RNA (Antao et al. 1991; Heus and Pardi 1991; Pley et al. 1994a,b; Wimberly 1994). A central feature of this motif is a sheared GA base pair (Fig. 1D). Such side-by-side pairing (shown red in Fig. 2A) reorients the RN A backbone relative to a Watson-Crick base pair (arrow in Fig. 2B). The pattern of stacking in boxB is extended by an aromatic side chain in the peptide: Tryptophan acts as a pseudo- 

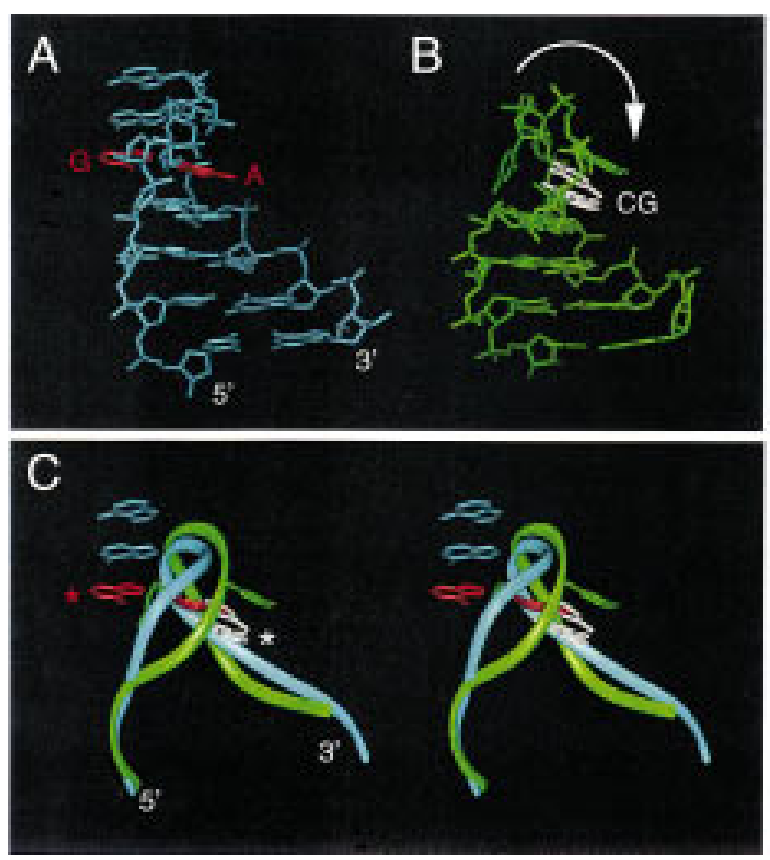

Figure 2. (A) Crystal structure of a GNRA (GAAA) tetraloop (Pley et al. 1994b; Brookhaven Databank accession no. 1HMH). The closing sheared GA base pair is shown in red; the structure is otherwise shown in cyan. (B) Solution structure of a nonGNRA (CUUG) tetraloop ( $F$. Jucker and $A$. Pardi, in prep.; Brookhaven Databank accession no. IRNG). The closing Watson-Crick GC base pair is shown in white; the structure is otherwise shown in green. The arrow indicates overall reorientation of the loop and redirection of CG base pair. (C) Comparison of tetral oop structures. The two structures are aligned according to the backbone atoms of the stem. The coloring scheme is as in A and B. The pairing scheme of the closing base pair (sheared GA vs. Watson-Crick CG) defines the orientation of the loop relative to the stem.

base at the $\mathrm{N}$-binding surface. Extended peptide-RNA stacking is coupled to induction of a specific internal RNA architecture and is blocked by RNA mutations associated in vivo with loss of antitermination activity (Doelling and Franklin 1989; Chattopadhyay et al. 1995a). Comparison of active and inactive RN A variants demonstrates the role of an inducible RNA structure in a genetic switch.

\section{Results}

A model of the $\lambda \mathrm{N}$ antitermination complex is provided by a 15-base RNA hairpin (nutL boxB 5'-GCCCUGAAGAAGGGC-3'; the underlined pentaloop is shown in Fig. 1B) and the amino-terminal 21 residues of the $\mathrm{N}$ protein without initiator methionine (designated $\lambda_{\mathrm{P} 1}$; Lazinski et al. 1989; Tan and Frankel 1995). The peptide-RNA dissociation constant $\left[\mathrm{K}_{\mathrm{d}} 6 \mathrm{~nm}\right.$ at $4^{\circ} \mathrm{C}$, as determined by gel retardation ( $T$ an and Frankel 1995; Cilley and Williamson 1997)] is similar to that of the intact protein (1.3 nм; Chattopadhyay et al. 1995a; Van
Gilst et al. 1997). The strength of the binding of $\lambda_{\mathrm{P} 1}$ to variant RN A sites (Table 1) correl ates with efficiency of $\mathrm{N}$-directed transcriptional antitermination (Doel ling and Franklin 1989; Chattopadhyay et al. 1995a; Mogridge et al. 1995); $\lambda_{\mathrm{P} 1}$ does not bind to segmental DNA analogs (Table 1 footnote). Circular dichroism (CD) spectra of $\lambda_{\mathrm{P} 1}$, boxB RNA, and their specific complex demonstrate that whereas the isolated peptide exhibits a largely random coil spectrum (Tan and Frankel 1995), the bound peptide exhibits an $\alpha$-helix content of $80 \%$ (Table 2; Su et al. 1997). RNA-directed folding of the peptide thus recapitulates that of the intact $\mathrm{N}$ protein (Van Gilst et al. 1997). In each case, RNA-dependent quenching of the intrinsic fluorescence of Trp-18 enables weak dissociation constants to be measured (Table 1 ) and provides a structural probe of the peptide-RN A interface (Van Gilst et al. 1997).

\section{A flexible RNA hairpin adopts a precise structure on peptide binding}

The base and anomeric (ribose $\mathrm{H}_{1^{1}}$ ) ${ }^{1} \mathrm{H}$ and ${ }^{13} \mathrm{C}$ nuclear magnetic resonance (NMR) spectra of boxB RNA have been assigned (Varani and Tinoco 1991) in the absence and presence of $\lambda_{\mathrm{P} 1}$ peptide (Fig. 3). The free RN A consists of a stem and a flexible loop. Its imino ${ }^{1} \mathrm{H}-\mathrm{N} M R$ spectrum contains three sharp resonances (12-14 ppm), assigned to the central CG base pairs of the stem (spectrum $b$ in Fig. 3A). The resonances of base pairs 1 and 5 are broadened by exchange with water (due to "fraying" of the double helix). A broad imino resonance is also observed at $10.75 \mathrm{ppm}$ and assigned below to a fraying GA base pair (G6-A10; see below). Stacking of G6 over U 5 is indicated by a nuclear Overhauser enhancement (NOE) between $\mathrm{G} 6-\mathrm{H}_{8}$ and $\mathrm{U} 5-\mathrm{H}_{6}$ of intensity si milar to that between $\mathrm{G} 12-\mathrm{H}_{8}$ and $\mathrm{G} 13-\mathrm{H}_{8}$ in the stem. Although no contacts are observed between base protons in the loop at $25^{\circ} \mathrm{C}$ in $\mathrm{D}_{2} \mathrm{O}$ (observation is restricted in part by limited dispersion of chemical shifts), the presence of selected nonsequential base-ribose NOEs (A 8- $\mathrm{H}_{8} / \mathrm{A} 10-$ $\mathrm{H}_{1}$ ) and absence of some sequential base-ribose NOEs $\left(\mathrm{A} 7-\mathrm{H}_{8} / \mathrm{A} 8-\mathrm{H}_{1}\right.$, and $\mathrm{A} 8-\mathrm{H}_{8} / \mathrm{G} 9-\mathrm{H}_{1}$ ) suggest that a nascent nonrandom structure is present but unstable. In contrast, the bound RN A is well-organized at $25^{\circ} \mathrm{C}$. Basepairing and -stacking are maintained in the stem and extend into the loop. The imino resonance of $U 5$ is sharp in the complex (asterisk at 13.5 ppm in Fig. 3A, spectrum c), indicating that its pairing with $A 11$ is stabilized on peptide binding. Retention of NOEs between successive base pairs in the stem indicates that the pepti de does not intercal ate or induce RN A base-flipping in this region.

Upon peptide binding, large changes in ${ }^{1} \mathrm{H}$ and ${ }^{13} \mathrm{C}$ chemical shifts occur throughout the RN A (RN A “complexation" shifts, illustrated in Fig. 3A). No correlation is observed between sites of large or small RNA complexation shifts and the asymmetric RNase footprint of protein binding (5' eight bases, 5'-GCCCUGAAGAAGGGC-3'; Chattopadhyay et al . 1995a). Such lack of correlation suggests that upon peptide binding the 
Table 1. Relative N peptide- and protein-RNA affinities

\begin{tabular}{|c|c|c|c|c|c|}
\hline \multirow[b]{2}{*}{ Analog } & \multicolumn{5}{|c|}{ Relative affinity } \\
\hline & $N$ peptide $\lambda_{P 1}$ & peptide $2^{\mathrm{a}}$ & $\mathrm{N}$ peptide $3^{\mathrm{b}}$ & $\mathrm{N}$ protein $1^{\mathrm{C}}$ & $\mathrm{N}$ protein $2^{\mathrm{d}}$ \\
\hline Wild-type boxB & $100 \%$ & $100 \%$ & $100 \%$ & $100 \%$ & $100 \%$ \\
\hline boxB DNA ${ }^{e}$ & N.D. ${ }^{f}$ & $-^{\mathrm{g}}$ & - & N.S. ${ }^{h}$ & - \\
\hline \multicolumn{6}{|l|}{ boxB RNA variants } \\
\hline $\mathrm{G} 6 \rightarrow \mathrm{C}(\mathrm{GCCCUCAAGAAGGGC})$ & N.S. & - & - & N.D. & N.D. \\
\hline $\mathrm{G} 6 \rightarrow \mathrm{A}(\mathrm{GCCCUAAAGAAGGGC)}$ & N.S. & N.D. & $\lessdot 0.5 \%$ & N.S. & - \\
\hline $\mathrm{G} 6 \rightarrow \mathrm{U}(\mathrm{GCCCUUAAGAAGGGC})$ & - & - & - & N.D. & - \\
\hline $\mathrm{G} 6 \rightarrow \mathrm{I}(\mathrm{GCCCU}$ IAAGAAGGGC) & N.S. & - & - & N.S. & - \\
\hline $\mathrm{A} 7 \rightarrow \mathrm{G}(\mathrm{GCCCUGGAGAAGGGC)}$ & $90 \%$ & $6 \% *$ & - & $100 \%$ & - \\
\hline$A 7 \rightarrow U(G C C C U G U A G A A G G G C)$ & $4 \%{ }^{i}$ & - & - & $100 \%$ & - \\
\hline $\mathrm{A} 7 \rightarrow \mathrm{C}(\mathrm{GCCCUGCAGAAGGGC)}$ & $2 \%-4 \%$ & - & - & $100 \%$ & $50 \%-100 \%$ \\
\hline $\mathrm{A} 8 \rightarrow \mathrm{G}(\mathrm{GCCCUGAGGAAGGGC)}$ & $40 \%$ & - & - & $100 \%$ & - \\
\hline$A 8 \rightarrow C($ GCCCUGACGAAGGGC) & - & - & - & $5 \%$ & $<10 \%$ \\
\hline $\mathrm{A} 8 \rightarrow \mathrm{U}(\mathrm{GCCCUGAUGAAGGGC})$ & $3 \%{ }^{i}$ & - & $2-3 \%$ & $5 \%$ & - \\
\hline $\mathrm{G} 9 \rightarrow \mathrm{C}(\mathrm{GCCCUGAACAAGGGC)}$ & - & - & $100 \%$ & $100 \%$ & - \\
\hline $\mathrm{G} 9 \rightarrow \mathrm{U}(\mathrm{GCCCUGAGUAAGGGC)}$ & $100 \%$ & - & - & $100 \%$ & - \\
\hline $\mathrm{G} 9 \rightarrow \mathrm{A}(\mathrm{GCCCUGAGAAAGGGC})$ & - & & $100 \%$ & $100 \%$ & $100 \%$ \\
\hline$A 10 \rightarrow C(G C C C U G A G A C A G G G C)$ & $6 \%{ }^{i}$ & - & $<1 \%$ & $25 \%-100 \%{ }^{j}$ & N.D. ${ }^{k}$ \\
\hline$A 10 \rightarrow G(G C C C U G A G A G A G G G C)$ & - & N.D. & - & $100 \%$ & - \\
\hline$A 10 \rightarrow U(G C C C U G A G A U A G G G C)$ & - & - & - & $12 \%-100 \% !$ & - \\
\hline
\end{tabular}

${ }^{a}$ Data were obtained from Tan and Frankel (1995) using peptide $\mathrm{N}$ amino acids 1-22, including initiator methionine.

${ }^{b}$ Data obtained from Cilley and Williamson (1997) using peptide $\mathrm{N}$ amino acids 2-19.

'Data obtained from Chattopadhyay et al. (1995a) and Van Gilst et al. (1997) using native N protein.

${ }^{\mathrm{d} D}$ ata obtained from Mogridge et al. (1995) using native $\mathrm{N}$ protein.

'Four DNA analogs were tested in the present study: all DNA as in Van Gilst et al. (1997); and three RNA-DNA hybrids (5'GCCCUGAAGAAGGGC, 5'-GCCCUGAAGAAGGGC, and 5'-GCCCUGAAGAAGGGC; underlined bases represent deoxyribonucleotides).

${ }^{f}(\mathrm{~N} . \mathrm{D}$.$) N o shifted band was detected.$

$g(-)$ Assay not performed.

h(N.S.) Binding was nonspecific (affinity 1000-fold less than specific binding; Van Gilst et al. 1997).

'Values measured by tryptophan fluorescence.

${ }^{\mathrm{j}} 100 \%$ binding was observed by GMSA, but only $25 \%$ relative affinity was obtained by competition with the native site (A. Das, pers. comm.).

${ }^{k}$ Discrepancy between studies (c,d) may be attributable to differences in exact gel-shift conditions (including temperature of the gel as a function of el ectrophoresis current) and confounding effects of kinetic instability [T an and Frankel (1995), column 2].

'Value of $100 \%$ was obtained by GMSA (Chattopadyay et al. 1995a) and 12\% by fluorescence (Van Gilst et al. 1997).

$\left.{ }^{*}\right)$ We cannot account for the difference in peptide binding to the A 7G RN A site between the present study (column 1) and that of Tan and Frankel (1995; column 2). In the present study near-native affinity is observed by both gel retardation and fluorescence assays.

RNA undergoes a global change in structure or dynamics. Of particular interest, $\mathrm{G} 6$ (the first base of the pentaloop) yields a narrow imino resonance at 11 ppm (asterisk in Fig. 3A, spectrum c). The importance of $\mathrm{G} 6$ is highlighted by the genetic selection of mutations at this position (Salstrom and Szybal ski 1978) associated with loss of $\mathrm{N}$-dependent antitermination (Fig. 1C; Doelling and Franklin 1989). Evidence for a G6-A 10 base pair is provided by three observations. First, the chemical shifts of the exocyclic amino resonances of each purine are widely inequival ent, diagnostic in each case of hydrogen bonding. Second, NOEs demonstrate that G6 is stacked over U5, whereas A10 overlies A11; furthermore, crossstrand contacts are observed between $\mathrm{A} 11-\mathrm{H}_{2}$ and $\mathrm{G} 6-$ $\mathrm{H}_{1}$. Third, indirect N OEs are observed between the G6 imino and $\mathrm{A} 10$ amino protons under experimental conditions in which spin diffusion is not observed between successive base pairs in the stem.

In conventional GA pairing schemes (characterized by anti-anti and anti-syn glycosidic torsion angles) the guanine imino proton participates in hydrogen bonding. In the boxB complex the $\mathrm{G} 6$ imino resonance remains in the upfield region (11 ppm), uncharacteristic of such schemes. The $\mathrm{G} 6$ imino proton makes no direct contacts with either $\mathrm{A} 10-\mathrm{H}_{2}$ (excluding formation of an anti-anti GA base pair) or $\mathrm{A} 10-\mathrm{H}_{8}$ (excluding formation of either an anti-syn GA base pair or the side-by-side GA base pair of an RN A aptomer; Fan et al. 1996). These observations (providing evidence of absence rather than absence of evidence) suggest by elimination that G 6 and A 10 form a sheared GA pair (reverse Hoogsteen), a pairing scheme first observed in the GNRA tetral oop (Fig. 1D). Formation of a sheared GA base pair is corroborated by observation of a diagnostic spin-diffusion NOE spectrocopy (NOESY) cross peak (mixing time, $300 \mathrm{msec}$ ) from the G6 imino resonance to the $\mathrm{A} 10-\mathrm{H}_{8}$ (but not to $\mathrm{A} 10-\mathrm{H}_{2}$ ). The sheared geometry rational izes the otherwise anomalous $\mathrm{H}_{1}$, chemical shift of $A 11$, whose upfield position 
Table 2. Summary of $C D$ and fluorescence results

\begin{tabular}{lcc}
\hline RN A analog & $\Delta \theta^{\mathrm{a}}-(222 \mathrm{~nm})$ & Fluorescence quenching \\
\hline Wild type & $-25,000$ & 0.25 \\
G6 $\rightarrow$ C & $-12,000$ & $0.85^{*}$ \\
G6 $\rightarrow$ I & $-6,000$ & $0.82^{*}$ \\
A $\rightarrow$ G & $-24,000$ & 0.31 \\
A $\rightarrow$ U & $-18,000$ & $0.47^{*}$ \\
A $\rightarrow$ G & $-25,000$ & 0.24 \\
A8 $\rightarrow$ U & $-5,000$ & $0.53^{*}$ \\
G9 $\rightarrow$ U & $-25,000$ & 0.26 \\
A $10 \rightarrow C$ & $-15,000$ & $0.75^{*}$
\end{tabular}

${ }^{a}$ Values shown represent the difference in mean residue ellipticity at $222 \mathrm{~nm}$ between the complex and the sum of the spectra of its constituents (free peptide and free RN A). Spectra were normalized with respect to the peptide concentration; values shown are given to nearest thousand. A helix content of $100 \%$ at $4^{\circ} \mathrm{C}$ corresponds to a $[\theta]_{222}$ value of $-34,000$.

${ }^{\mathrm{b}}$ Fluorescence quenching is represented as the ratio of intensities at $350 \mathrm{~nm}$ of the bound and free peptides after correction of the latter for the inner filter effect. The excitation wavel ength was $295 \mathrm{~nm}$. Values $<1$ represent quenching of intrinsic tryptophan fluorescence. Asterisks indicate attenuation of RNA-induced blue shift as illustrated in Fig. 4A.

(4.99 ppm; Fig. 3B) is characteristic of the $3^{\prime}$ nucleoside of the closing base pair of the GNRA tetral oop (Orita et al. 1993).

Whereas the sheared GA base pair in boxB is associated with sequential and nonsequential contacts in the pentaloop, no base-base contacts are observed from G6 to $A 7$, from $A 8$ to $G 9$, or from $G 9$ to $A 10$. The bound RNA thus assumes a specific pattern of base-pairing, base-stacking, and base-flipping as illustrated in Figure 1B. This structure is remarkable for successi ve stacking of $A 7, A 8$, and the sheared GA base pair. The core of the induced RNA structure is analogous to that of the GAAA tetral oop (Fig. 2A; Jucker et al. 1996). A pental oop differs from a tetraloop in that it has an extra base. The odd base is G9, which exhibits no sequential NOEs to adjoining bases. The $\mathrm{G} 9$ ribose exhibits $\mathrm{C} 2$ ' endo pucker [as indicated by the anomal ous intensity of cross peaks in doublequantum filtered correlation spectroscopy (DQF-COSY) and total correlation spectroscopy (TOCSY) spectra], and its glycosidic torsion angle is syn (as indicated by the anomal ous intensity of the $\mathrm{G} 9 \mathrm{H}_{8}^{-}$ $\mathrm{H}_{1}$, NOE; Fig. 3B). $\mathrm{N}$ ot essential for $\mathrm{N}$ binding (Table 1 ), the flipped base (G9) nevertheless contributes to bi ological activity (Fig. 1C; Doelling and Franklin 1989). [The term base-flipping (Roberts 1995) is meant in the broad sense of protein recognition of an exposed, unstacked, and unpaired base and is not meant to suggest that purine $\mathrm{G} 9$ is extruded from an RN A doublehelix on peptide binding.] The pattern of base-stacking is extended the top of the structure by direct stacking between the purine ring of $\mathrm{A} 7$ and the indole ring of Trp-18 (Fig. 1B; Su et al. 1997). Such stacking rational izes the quenching of tryptophan fluorescence on boxB binding (van Gilst et al. 1997) and a functional requirement for an aromatic amino acid at this position (Franklin 1993).
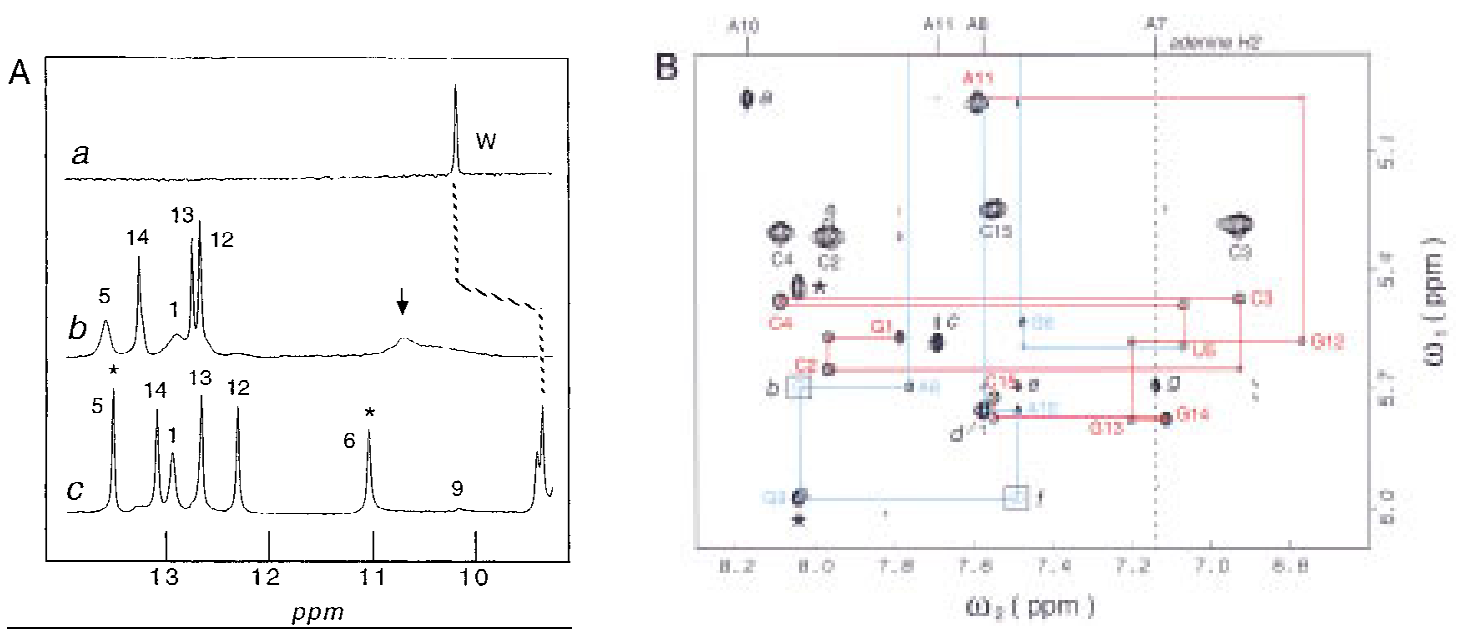

Figure 3. (A) $1 \mathrm{D}{ }^{1} \mathrm{H}-\mathrm{N} \mathrm{MR}$ spectra in $\mathrm{H}_{2} \mathrm{O}$ at $400 \mathrm{M} \mathrm{hz}$ and $25^{\circ} \mathrm{C}$ : (a) Free $\lambda_{\mathrm{P} 1}$ with unique tryptophan (Trp-18) indole $\mathrm{N} \mathrm{H}$ resonance; (b) free boxB RN A hairpin with imino resonances assigned as indicated. G1 and U 5 exhibit partial broading at ends of stem. The arrow indicates additional unassigned broad imino resonance of guanine (10.75 ppm), presumably representing a fraying GA base pair. (c) Spectrum of specific complex with imino resonances assigned as indicated. Asterisks indicate sharp downfield imino resonance of $U 5$ and sharp but upfield imino resonance of G6, proposed to participate in a sheared GA base pair (Fig. 1D). The indole N H resonance of Trp-18 exhibits a 0.9 ppm upfield complexation shift (broken line; see Fig. 5A). The peptide and RN A were each 2 mm (B) Sequential assignment of RNA in the $\lambda_{\mathrm{P} 1}$, complex at $25^{\circ} \mathrm{C}$ and $750 \mathrm{M} \mathrm{Hz}$. Connectivities in stem and loop are shown in red and blue, respectively. Positions of adenine $\mathrm{H}_{2}$ resonances are indicated at top. The broken line indicates only a single $\mathrm{NOE}$ from the $\mathrm{H}_{2}$ of $\mathrm{A} 7 \mathrm{in}$ this region (cross peak $\mathrm{g}, \mathrm{A} 7-\mathrm{H}_{2} / \mathrm{A} 8-\mathrm{H}_{1^{\prime}}$ ). The asterisk indicates NOE between $\mathrm{G} 9-\mathrm{H}_{8}$ and $\mathrm{G} 9-\mathrm{H}_{3}{ }^{\prime}$, the latter at an anomalous chemical shift. Assignment of cross peaks a, A 10- $\mathrm{H}_{2} / \mathrm{A} 11-\mathrm{H}_{1} ; \mathrm{c}, \mathrm{A} 11-\mathrm{H}_{2} / \mathrm{G} 6-\mathrm{H}_{1}$ ( (immediately bel ow is the larger A 11- $\mathrm{H} 2 / \mathrm{U} 5-\mathrm{H}_{1}$ ); d, A8- $\mathrm{H}_{2} / \mathrm{A} 10-$ $\mathrm{H}_{1^{\prime}}$; and e, A 10- $\mathrm{H}_{8} / A$ 8- $\mathrm{H}_{1^{\prime}}$. Boxes $\mathrm{b}$ and $\mathrm{f}$ indicate missing N OEs between nucleosides 8-9 and 9-10, respectively, reflecting flipping out of $\mathrm{G} 9$ (see Fig. 1B). 
The GA base pair is essential for peptide-induced fit and biological activity

G6 and A10 are each essential for biological activity (Fig. 1C; Doelling and Franklin 1989). Although the functional requirement for adenine is absol ute (Fig. 1C; Doelling and Franklin 1989), C 10, U 10, and G10 may in principle pair with $\mathrm{G} 6$ and provide alternative bridges across the RN A loop. The ${ }^{1} \mathrm{H}-\mathrm{N}$ M R spectrum of the free A $10 \mathrm{C}$ RNA (Fig. 4C) demonstrates that the variant site contains the expected GC base pair (arrow) and is more stably folded than the unbound native RNA: In the absence of peptide U5-A11 and non-native G6-C10 base pairs exhibit (in contrast to native boxB) little or no broadening due to fraying. $\lambda_{\mathrm{P} 1}$ binds with decreased affinity and reduced kinetic stability to this structure (Table 1; Cilley and Williamson 1997). Although the A10C peptide dissociation constant is estimated to be $100 \mathrm{~nm}$ at $4^{\circ} \mathrm{C}$ by fluorescence (Table 1 ), no binding is detectable at this concentration by the standard gel mobility-shift assay (GMSA). The induced fit of the peptide (Su et al . 1997), as monitored by CD (signal a in Fig. 4B), is disrupted (estimated $\alpha$-helix content $<50 \%$; Table 2 ). Likewise, the CD signature of induced fit in the RN $A$ is absent (signal b in Fig. 4B). Quenching of Trp-18 fluorescence in the $A 10 C$ complex is incomplete (Fig 4A; Table 2). The ${ }^{1} \mathrm{H}-\mathrm{NMR}$ spectrum of the $\mathrm{A} 10 \mathrm{C}$ variant complex (Fig. 4D) reveals two modes of binding in slow exchange on the ${ }^{1} \mathrm{H}-\mathrm{N}$ M R chemical-shift time scale ( $>10$ msec). G6 substitutions are likewise associated with attenuation of peptide-induced fit and inefficient quenching of tryptophan fluorescence (Table 2). G6 $\rightarrow \mathrm{C}$ and $\mathrm{G} 6 \rightarrow$ I (inosine) variants form weak equimolar peptide complexes ( $K_{d} 0.5 \mu$; Table 1$)$, a value similar to the non-specific RNA-binding affinity of the intact $\mathrm{N}$ protein (1.5 $\mu \mathrm{m}$; Van Gilst et al. 1997).

\section{Stacking of tryptophan with a pyrimidine is incomplete and unstable}

Direct stacking between the purine ring of $A 7$ and the indole ring of Trp-18 in the peptide (Su et al. 1997) is associated with a functional requi rement for an aromatic amino acid at this position of the protein (tryptophan or tyrosine; Franklin 1993) and a purine at RN A position 7 (Fig. 1C; Doelling and Franklin 1989). The peptide binds with essentially native affinity to an A7G RNA analog but with 20-fold decreased affinity to an A7U analog (Table 1). The extent of shifted complex as observed by gel electrophoresis (Fig. 5E) is less than would be predicted by the equilibrium constant, suggesting that the variant complex partially dissociates on the time scale of electrophoresis (Cilley and Williamson 1997). Native
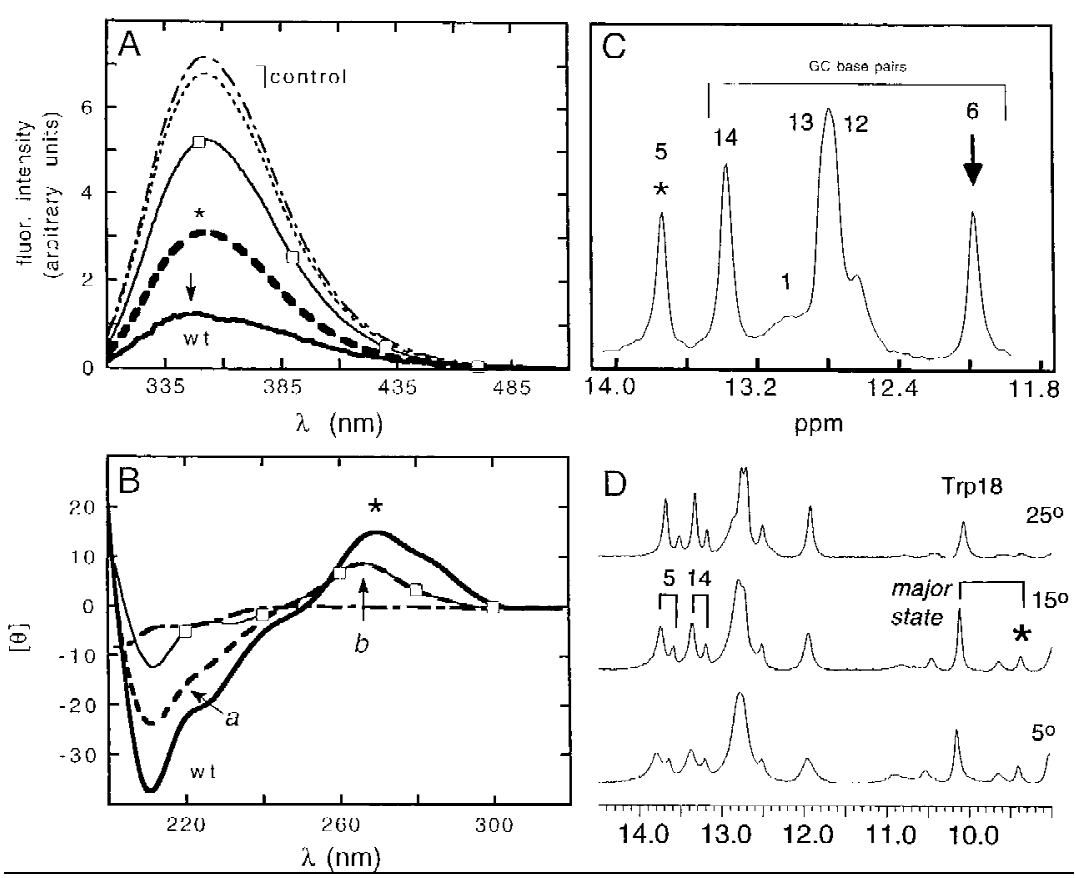

Figure 4. (A) Tryptophan fluorescence spectra of of the free peptide (open boxes), native complex (solid line), and variant complex C10 complex (thick dashed line). Peptide and RN A concentrations were $5 \mu \mathrm{m}$. A control for the inner filter effect is shown in the two upper control spectra: free peptide $(-\cdot-)$ and an equimolar mixture of free peptide and free RNA (---) in $2 \mathrm{M} \mathrm{KCl} \mathrm{(pH} \mathrm{7.4).} \mathrm{(B)} \mathrm{CD} \mathrm{spectra}$ of the free C10 RNA (open boxes), free peptide $(-\cdot-)$, and variant complex (thick dashed line). A reference spectrum of the native complex is also shown (wt; solid line). Deconvolution of the wild-type difference spectrum suggests that 16 residues are helical in the bound state. The arrow (a) indicates an attenuated signal at the helix-sensitive wavelength, $222 \mathrm{~nm}$. The asterisk indicates RN Aspecific perturbation in the native complex; its attenuation in the variant complex is label ed at arrow $b$. This perturbation, similar to that of a Rev-RRE complex (T an and Frankel 1994), is not amendable to detailed interpretation. Analysis of difference spectra reveals attenuation of induced $\alpha$-helix content (see Table 2 and footnote). Peptide and RN A concentrations were $25 \mu \mathrm{m}$. (C) $400-\mathrm{MHz}$ ${ }^{1} \mathrm{H}-\mathrm{NMR}$ spectrum of amino protons in the C10 RNA variant demonstrate stabilization of the U5-A11 base pair (asterick) and extension of the stem to G6-C10. Assignments are as indicated; the arrow indicates the new G 6 imino resonance of the GC base pair. (D) $600 \mathrm{M} \mathrm{Hz}{ }^{1} \mathrm{H}-\mathrm{N} \mathrm{MR}$ spectra of $1: 1$ peptide-A $10 \mathrm{C}$ RN A complex at $5^{\circ} \mathrm{C}, 15^{\circ} \mathrm{C}$, and $25^{\circ} \mathrm{C}$. Corresponding resonances in major and minor states are outlined; the asterisk indicates upfield indole N H resonance of Trp-18 in the minor state. In the major mode the RN A chemical shifts are similar to those of the free RN A; the chemical shifts of Trp-18 (but not those of amino acids such as Thr-5) are near those of the free peptide. In the minor mode these chemical shifts resemble those of the native complex, including the indole ring's large upfield compl exation shift. The ratio of major to minor populations increases with increasing temperature. Spectra were obtained at a complex concentration of $1 \mathrm{~mm}$ in $50 \mathrm{~mm} \mathrm{NaCl}$ and $10 \mathrm{~mm}$ sodium phosphate (pH 6.0). 


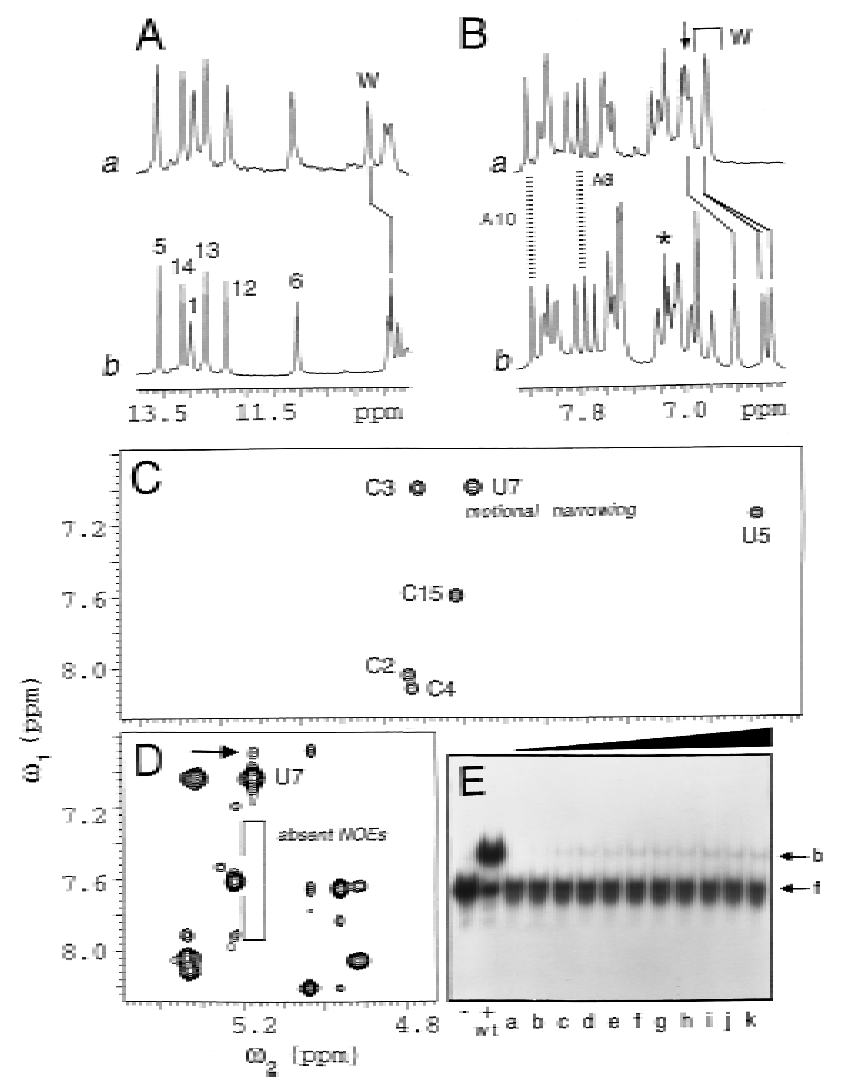

Figure 5. ${ }^{1} \mathrm{H}-\mathrm{NMR}$ analysis of $\mathrm{A} 7 \mathrm{U}$ variant complex. (A, B) Imino and nonexchangable aromatic resonances of the native (b) and variant (a) complexes. Large changes in Trp-18-specific resonances are shown as solid vertical lines (A); constancy of A10$\mathrm{H}_{2}$ and $\mathrm{A} 8-\mathrm{H}_{2}$ resonances are shown as broken vertical lines. Assignment of imino resonances is as indicated. $\mathrm{H}_{2} \mathrm{O}$ and $\mathrm{D}_{2} \mathrm{O}$ spectra were collected at 400 and $600 \mathrm{MHz}$, respectively, at $25^{\circ} \mathrm{C}$. (C) TOCSY spectrum of A7U complex (mixing time 55 msec at $25^{\circ} \mathrm{C}$ at $600 \mathrm{MHz}$ ) reveals motional narrowing of $\mathrm{U} 7$ base protons relative to cytosine and uridine resonances in the stem. The chemical shifts of these major groove pyrimidine resonances are not significantly changed by the $A 7 U$ substitution. (D) NOESY spectrum in $\mathrm{D}_{2} \mathrm{O}$ (mixing time $300 \mathrm{msec}$ at $25^{\circ} \mathrm{C}$ and $600 \mathrm{M} \mathrm{Hz}$ ) shows weak contact between Trp-18 indole ring $\left(\mathrm{H}_{5}\right)$ and $\mathrm{U} 7-\mathrm{H}_{5}$ (arrow) but no other $\mathrm{U}$ 7-base contacts. (box) The A 7U complex was made $1 \mathrm{~mm}$ in NMR buffer. (E) GMSA showing weak binding of the $A 7 \mathrm{U}$ RN A (a-k) at concentrations $0,10,20,30,40,50,60,70,80,90$, and $100 \mathrm{~nm}$. A wild-type control is provided in the first two lanes. The dissociation constant as measured by fluorescence quenching is $\sim 125 \mathrm{~nm}$ (Table 1); the disproportionately weak gel shift is attributable in part to kinetic instability of the complex during the course of electrophoresis.

and $A 7 U$ variant complexes exhibit a marked difference in the extent of the quenching of Trp-18 fluorescence (Table 2); furthermore, the variant complex (unlike the wild type) exhibits no blue shift of its fluorescence emission maximum (asterisk in Table 2). These observations demonstrate that the decrement in peptide-RN A affinity is associated with a qual itative change in local structure: incompl ete stacking of T rp-18 on the smaller pyrimidine ring. This, in turn, is associated with a small abridge ment of RNA-dependent folding of the peptide (reduction in negative ellipticity at $222 \mathrm{~nm}$; Table 2). In contrast, fluorescence and CD spectra of an A7G complex are similar to those of the wild-type complex (Table 2). ${ }^{1} \mathrm{H}-\mathrm{N}$ MR studies of the A7U complex demonstrate that the induced RNA structure is similar to that of the native complex. Stem-specific chemical shifts of imino (Fig. 5A) and major groove pyrimidine (Fig. 5C) resonances are essentially identical in the native and variant complexes. This correspondence indicates that the substitution in the RNA loop does not perturb the docking of the peptide in the RNA stem. Likewise unchanged are chemical shifts of structure-sensitive $\mathrm{H}_{2}$ protons of internal adenines in the loop (A8 and A 10; broken vertical lines in Fig. 5B). As expected, chemical shifts of Trp-18 aromatic protons are in each case downfield of their frequencies in the wild-type complex (solid vertical lines in Fig. 5, A and B), representing an attenuation of the upfield complexation shifts characteristic of the wild-type complex (Fig. 5A; Su et al. 1997). This attenuation is presumably due (at least in part) to the smaller aromatic ring current of a pyrimidine relative to that of a purine. The aromatic resonances of $U 7$ (unlike those of A7) exhibit relative motional narrowing (as seen in the intensity of and resolved coupling within the U 7 TOCSY cross peak; Fig. 5C). Such resonance narrowing indicates that the pyrimidine ring has enhanced mobility on a time scale more rapid than that of overall tumbling of the complex ( $<2$ nsec), that is, the U 7-Trp-18 contact is unstable at the peptide-RNA interface. No NOEs are observed between $U 7$ and $A 8$ analogous to those be tween $A 7$ and $A 8$ in the native complex (Table 2). Despite these dynamic perturbations, close spatial proximity of Trp-18 and U 7 is on average maintained, as shown by a weak intermolecular NOE (arrow in Fig. 5D); nonspecific spin diffusion is excluded by the absence of contacts between $U 7$ and other bases in the pentaloop (empty rectangle in Fig. 5D).

A specific internal RNA architecture is required for tryptophan stacking at one RNA surface and for NusA binding at the other

boxB RNA exhibits an analogous purine requirement at position 8 (Fig. 1C). ${ }^{1} \mathrm{H}-\mathrm{NMR}, \mathrm{CD}$, and fluorescence spectra of the active A $8 G$ variant complex exhibit native features. The substitution A8U is associated with essentially complete loss of activity (Doelling and Franklin 1989). The variant RN A peptide dissociation constant is reduced $\left(\mathrm{K}_{\mathrm{d}} 150 \mathrm{~nm}\right.$; Table 1$)$. Fluorescence spectra of native and $\mathrm{A} 8 \mathrm{U}$ variant complexes reveal marked attenuation of the quenching of Trp-18 (Table 2). This perturbation is indirect, as Trp-18 and A 8 are not in contact. These observations suggest that external stacking of Trp18 and $A 7$ requires a purine-specific internal RNA architecture. The U 8-, but not G8-, variant complex also exhibits a dramatic abridgement of the $\alpha$-helical transition induced in the native peptide-RNA complex (Table 2). The block to peptide folding in the U 8 complex is greater 
than that observed in the $U 7$ complex. This perturbation, presumably transmitted through the RN A (Fig. 1B), recapitulates the folding requirements of a GNRA tetral oop (Jucker et al. 1996). These results demonstrate a physical coupling between an induced RN A architecture and peptide folding. This coupling correlates in turn with antitermination activity in vivo (Fig. 1C; Doelling and Franklin 1989).

Although the flipped base $\mathrm{G} 9$ does not participate in the internal RNA architecture, its substitution by a pyrimidine causes a reduction in the efficiency of $\mathrm{N}$-directed antitermination (Fig. 1C; Doelling and Franklin 1989). Such substitutions do not affect the affinity of boxB for N (Chattopadhyay et al. 1995a; M ogridge et al. 1995) or N peptides (Table 1; Cilley and Williamson 1997). Reduction in biological activity correl ates instead with decreased affinity of the variant N-RNA complex for N usA and thus inefficient recruitment to the antitermination complex (Chattopadhyay et al. 1995a; Mogridge et al. 1995). As expected from the model (Fig. 1B), no N OEs are observed between G9 and the peptide in the N OESY spectrum of the native $\lambda_{P 1}$ complex. $N$ ative and G9U complexes exhibits identical fluorescence and CD spectra (Table 2).

\section{Discussion}

The $\lambda \mathrm{N}$ protein contains an arginine-rich motif characteristic of a diverse family of prokaryotic and eukaryotic RNA-binding proteins (Lazinski et al. 1989). Well-characterized examples are the T at and Rev proteins of mammalian immunodeficiency viruses (Tan et al. 1993; Battiste et al. 1994, 1996; Ye et al. 1995, 1996). A general feature of their RN A complexes is costabilization of peptide and RNA structures (Tan and Frankel 1995). The present study has focused on the organization of RNA within a boxB-N peptide complex (Lazinski et al. 1989; Tan and Frankel 1995). The bound RN A has been demonstrated to exhibit a specific pattern of base-pairing, base-stacking, and base-flipping (Fig. 1B). Comparison of active and inactive RN A variants strongly suggests that this pattern is required for biological activity.

boxB provides a structural switch in transcriptional antitermination

boxB provides an RNA tether that enhances the local concentration of $\mathrm{N}$ near its site of action. Does the RN A also act as a structural switch? This question was first motivated by characterization of base substitutions that reduce antitermination activity disproportionately to destabilization of $\mathrm{N}$ binding (Chattopadhyay et al. 1995a; Mogridge et al. 1995). Such mutations interfere with binding of the N-boxB complex to N usA and its subsequent assembly within the RNA polymerase (RNAP)antitermination machinery. Because boxB does not bind $\mathrm{N}$ usA in the absence of $\mathrm{N}$, an $\mathrm{N}$-induced change in RN A structure was predicted to define a novel recognition surface (Chattopadhyay et al. 1995a; M ogridge et al. 1995). This hypothesis is supported indirectly by the low effi- ciency of antitermination achieved by "swap" of the $\lambda \mathrm{N}$ argi nine-rich motif and boxB by anal ogous HIV-1 peptide and RN A motifs (TAT and tar; Harada et al. 1996). Here, we have tested a central feature of this hypothesis by investigation of the structure of box $B$ in the absence and presence of an arginine-rich $\mathrm{N}$ peptide (Lazinski et al. 1989; Tan and Frankel 1995). The structure of the unbound boxB contains a stem and flexible loop. Stable base-pairing and base-stacking are maintained in the stem, including the pairing of U 5 and $A 11$ and stacking of $\mathrm{G} 6$ over $\mathrm{U} 5$. We imagine that binding of the $\mathrm{N}$ peptide stabilizes a loop conformation, accessible at least in part to the free RNA. Such binding is associated with large changes in ${ }^{1} \mathrm{H}$ and ${ }^{13} \mathrm{C}$ chemical shifts throughout the stem and loop.

\section{The bound RNA mimics a GNRA tetraloop}

We propose an anal ogy between the induced structure of boxB and the GNRA tetraloop. This analogy is motivated by similarities in both function and structure. Each RN A presents a surface for higher-order assembly: Whereas the tetraloop mediates RNA-RNA assembly (Pley et al. 1994b; Wimberly 1994; Cate et al. 1996), boxB mediates protein-RNA-protein assembly (Chattopadhyay et al. 1995a; M ogridge et al. 1995). The RN A structures are in each case defined by patterns of basepairing (including non Watson-Crick base pairs), basestacking, and base-flipping (Fig. 2A; Heus and Pardi 1991; Pley et al. 1994a,b). The 5'-G and 3'-A form a sheared (reverse Hoogsteen) base pair over which is stacked a purine at position $3(\mathrm{R})$. The second base $(\mathrm{N})$ overlies the third and can be stably stacked (purine) or displaced (pyrimidine). Each contains a requisite purine at the third position of the loop, which is stacked over the GA base pair. Unlike the GNRA tetraloop, however, boxB is "incomplete" as a motif of RNA structure: Its folding requires peptide binding with indole-base stacking at the protein-RN A interface (Su et al. 1997). Such mimicry of a motif of RNA-RNA assembly by a protein-RN A complex may represent an early event in the transition between the proposed RN A and protein worlds.

The sheared GA base pair is required for biological activity and orients the RNA loop

The sheared GA base pair in boxB provides a physical bridge between opposing RN A surfaces. The orientation of this base pair (Fig. 1D) is distinct from that of other purine-purine base pairs, including those in Tat and Rev complexes (Puglisi et al. 1995; Ye et al. 1995; Battiste et al. 1996). In the GNRA tetral oop the sheared base pair specifies the orientation of the loop relative to the stem (Fig. 2A); its substitution by a Watson-Crick base pair is associated with a global realignment of the loop's position (arrows in Fig. 2, B and C). In boxB any base substitution of $\mathrm{G} 6$ or A 10 causes complete loss of biological activity (Fig. 1C; Doelling and Franklin 1989). Replacement of the GA base pair in boxB by a Watson-Crick GC would likewise be expected to reposition the pentaloop. 
Such an RNA variant, shown above to be in part preorganized, nevertheless forms a complex with reduced thermodynamic and kinetic instability (Mogridge et al. 1995; Cilley and Williamson 1997).

The present study demonstrates that a Watson-Crick bridge abridges peptide- and RNA-induced fit; the variant complex exhibits two distinct modes of binding. Based on the structures of variant tetraloops (Fig. 2), we propose that GA and GC boxB hairpins present distinct surfaces for peptide recognition: Global repositioning of the loop in the Watson-Crick analog precludes spatial complementarity to an induced peptide structure on one side and to N uSA and the N USA-RNAP antitermination complex on the other. Unlike substitution of A10 by $C$, an A10U variant induces in the $\mathrm{N}$ protein a native $\alpha$-helical transition with native fluorescence quenching (Van Gilst et al. 1997). We speculate that breakage of a GU base pair occurs in the complex and allows native positioning of the pentaloop, including stacking of A7 and Trp-18. The variant complex forms with high affinity but is without biological activity (Doelling and Franklin 1989; Chattopadhyay et al. 1995a).

Transcriptional antitermination requires a specific pattern of base-stacking and base-flipping

Efficient $\mathrm{N}$-directed antitermination requires purines at positions 7, 8, and 9 (Fig. 1C). The requirement at position 8 is enforced by stacking of the purine over the sheared GA base pair. Substitution by $U$ abridges induced fit of the peptide and the RNA. Purines at positions 7 and 9 -in contrast, not integral to the induced RNA structure-provide respective landmarks for recognition by $\mathrm{N}$ and the core antitermination complex. Substitution of $A 7$ by $U$ destabilizes its stacking with Trp-18 (on one side) and A8 (on the other), whereas the overall RNA structure is preserved. Although the U 7 RNA site exhibits a 12-fold loss of peptide affinity (Table 1), binding of the intact $\mathrm{N}$ protein to longer RNA fragments is not affected by pyrimi dine substitutions (Chattopadhyay et al. 1995a; Modridge et al. 1995). The discrepancy between affinities of the peptide and protein [al so observed by Cilley and Williamson (1997)] is likely to reflect additional protein-RNA contacts not present in the peptide-boxB model. Given that the binding properties of the intact protein are likely to be more relevant to activity, what enforces a functional requirement for a purine at position 7 (Fig. 1C)? We propose that A7 and Trp18 together define a recognition el ement for higher-order interaction with the N usA-RN AP complex and that dynamic instability of the joint Trp-18-U 7 surface interferes with such recognition. This proposal is supported by the observation that a $C 7$ boxB-N complex is not readily bound by $N$ usA nor recruited into higher-order RNAP complexes (Mogridge et al. 1995). A G9U variant exhibits native peptide binding and structure but is associated with partial loss of antitermination activity (Fig. 1C; Doelling and Franklin 1989). This loss correlates with impaired binding to a N usA-RN AP complex (Chattopadhyay et al. 1995a; M odridge et al. 1995). The relative biological activities of variants at position 9 ( $\mathrm{G}>\mathrm{A}>>\mathrm{U}>\mathrm{C}$; Fig. $1 \mathrm{C}$ ) are likely to reflect structural features of a binding pocket in N usA or the N usA-RN AP complex.

A puzzling result of genetic analysis (Franklin 1993) is the reported absence of mutations in $\lambda \mathrm{N}$ capable of suppressing specific loss-of-function associated with base substitutions in the pentaloop of box $\mathrm{B}$. This negative result is remarkable in light of the efficiency with which the protein's "sequence space" was apparently sampled in that study by random cassette mutagenesis. Absence of specific suppression (and, hence, of $\mathrm{N}$ domains with altered specificity) stands in contrast to the efficiency with which such mutations have been found in RevRRE (Rev response element) variants (Jain and Belasco 1996). Because, these systems otherwise exhibit marked similarities [including costabilization of peptide and RNA structures (T an and Frankel 1994)], why can base specificity be reprogrammed in one protein (Rev) but not in the other $(\lambda N)$ ? The present results suggest a structural explanation. We consider each position of the boxB pentaloop in turn. (1) Position 7. This base stacks with the indole ring of Trp-18. We speculate that such stacking requires an aromatic amino acid regardless of whether the base is a purine or pyrimidine. In contrast, sites of altered specificity in the Rev-RRE complex involve hydrogen bonds and van der Waal interactions between side chains and the edges of base pairs (Jain and Belasco 1996). (2) Position 9. The flipped base is proposed to contact the transcriptional machinery. Second-site mutations would thus map outsi de of $\mathrm{N}$ (e.g., in N usA). (3) Positions 6 and 10. Substitutions of the sheared GA base pair are likely to cause gl obal changes in the orientation or stability of the loop. Such changes may require a switch in overall strategy of recognition, unlikely to be associated with a single amino acid substitution. (4) Position 8. Substitution of the central purine by a pyrimidine is likewise predicted to redefine the overall structure or stability of the loop.

The boxB complex does not deliver a specific "go" signal to RNAP

RNA-directed assembly of an N-boxB-N usA complex within the core transcriptional machinery can serve either or both of two biochemical functions. First, contacts between $\mathrm{N}$-bound boxB and $\mathrm{N}$ usA may extend unrelated protein-protein interactions between the carboxy-terminal domain of $\mathrm{N}$ and NusA or RNAP (as in nut-independent antitermination; Rees et al. 1996). Such multidentate recognition would provide a mechanism of cooperativity in the higher-order assembly of a ribonucleoprotein complex (M ogridge et al. 1995). Second, the precise contacts by boxB within the antitermination complex could provide a specific antitermination signal, that is, an RNA-directed go switch may be thrown in RNAP (King et al. 1996). The latter mechanism is unlikely. Studies of the N un transcriptional termination protein of phage HK022 (Chattopadhyay et al. 1995b; Hung and Gottesman 1995) have defined an analogous 
arginine-rich motif (Fig. 6A) specific for $\lambda$ nut box B. Although $\mathrm{N}$ un and $\mathrm{N}$ have opposite functions (termination and antitermination; Hung and Gottesman 1995), the $\lambda \mathrm{N}$ arginine-rich motif in the intact $\mathrm{N}$ protein may be replaced by the $\mathrm{N}$ un arginine-rich motif without change in RNA-binding specificity or function (Henthorn and Friedman 1996). Swap of RNA-binding domains is thus not associated with an interchange of function. The $\mathrm{N}$ and $\mathrm{N}$ un arginine-rich motifs each contain aromatic side chains (boxed in Fig. 5A) and may exhibit similar mechanisms of RN A binding (Chattopadhyay et al. 1995b; M. Gottesman, pers. comm.). If their respective boxB complexes also interact similarly with the transcriptional machinery, these observations exclude the existence of a functionally specific (stop or go) binding site in the N usA-RNAP complex.

Structural determinants of $\mathrm{N}$-nut specificities among lambdoid phages P22 and $\phi 21$

Bacteriophages $\lambda, \mathrm{P} 22$, and $\phi 21$ exhibit similar genomic organizations, including phage-specific $\mathrm{N}$ proteins and nut sites (Franklin 1985a,b). Although the structures of P22 and $\phi 21$ boxB sites have not been characterized, in principle, each can form a nonstandard hairpin (Fig. $6 \mathrm{C}$,D). Will respective $\mathrm{N}$-boxB compl exes exhibit analogous modes of recognition? It is possible that the P22 complex will al so contain sheared GA (boxed in Fig. 6C) and closing UA base pairs. Furthermore, position 7 of P22 boxB sites is adenine, as in $\lambda$ nut sites. However, P22 nut sites contain a pyrimidine at position 8 (circled in Fig. 6C). This substitution-incompatible in $\lambda$ boxB with stable stacking over the GA base pair (asterisk in Fig. 6C) - presumably bl ocks formation of a heterol ogous $\lambda \mathrm{N}-\mathrm{P} 22$ boxB complex. This proposal is supported by the $>20$-fold enhancement in binding of a $\lambda \mathrm{N}$ peptide to a variant P22 boxB in which P22 positions 8 and 9 (5'CA) are replaced by the corresponding $\lambda$ boxB bases ( $5^{\prime}$ AG; T an and Frankel 1995). Together, these observations suggest that the P22 pentaloop adopts a structure distinct from that in $\lambda$ boxB and is recognized by a distinct mechanism. It is intriguing that the $\mathrm{P} 22 \mathrm{~N}$ arginine-rich motif also lacks an aromatic residue corresponding to $\lambda$ N Trp-18 (Fig. 6A, line 2; Franklin 1985b).

Inspection of putative $\phi 21$ boxB hairpins (Fig. 6D) reveals more marked difference in predicted loop size (six nucleosides), sequence (pyrimidine-rich), and possible base-pairing (an absence of a GA base pair; asterisks in

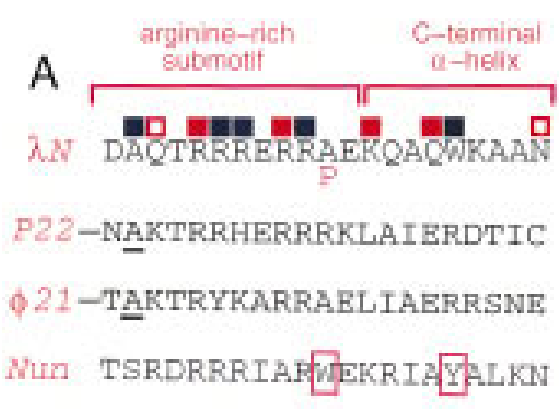

B

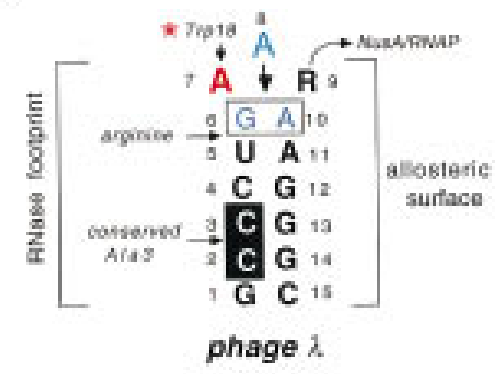

C

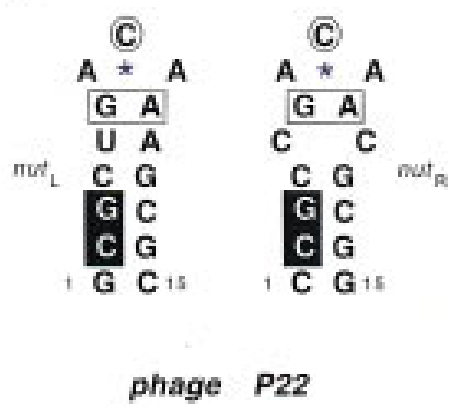

D

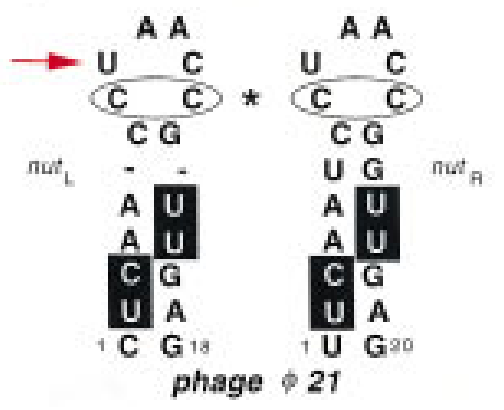

Figure 6. (A) Alignment of arginine-rich $N$ sequences in phages $\lambda, P 22$, and $\phi 21$ (Franklin 1985b; Chattapadhyay et al. 1995b) and termination factor $\mathrm{N}$ un of phage $\phi$ HKO22 (Hung and Gottesman 1995). Alanine conserved among N proteins is underlined. Dashes to the left of P22 and $\phi 21$ sequences indicate the presence of amino-terminal additional residues not in $\lambda \mathrm{N}$. Essential side chains (as inferred from genetic analysis; Franklin 1993) are indicated by dark blue squares (Ala-3, three of five arginines; and Trp-18); these have the most restricted patterns of allowed substitutions. Other contributing residues are indicated by red squares (solid >open), including two of five arginines. Substitution of proline at position 12 (P) confers native biological activity (Franklin 1993). (B-D) Comparison of boxB sites in lamboid phages. (B) Consensus boxB hairpin in phage $\lambda$ showing specific pattern of base-pairing and base-flipping (purines 7 and 9). Three sites of peptide-base contact (Su et al. 1997) are as indicated. The open box indicates a sheared GA base pair; the black box highlights the position of contact with Ala-3 in the major groove. The $\mathrm{RN}$ ase footprint of the $\mathrm{N}$ protein (Chattapadhyay et al. 1995a) is shown at left; the proposed al losteric surface involved in binding to the core antitermination complex is shown at right. (R) A functional preference or requirement for purine (Fig. 1C; Doelling and Franklin 1989). The proposed interaction of the flipped base (R9) with N usA in an antitermination complex is indicated. (C,D) Putative hairpin structures of boxB sites in phages P22 and $\phi 21$. P22 sites maintain possible GA base pair but lack a purine at position 8 (circle and asterisk); substitution of a purine enhances heterospecific binding of $\lambda \mathrm{N}$ peptide ( $T$ an and Frankel 1995). The putative P22 stem al so lacks a corrsponding CC element (black square). \$21 sites lack a possible GA base pair (oval and asterisk) and CC elements (black squares). Possible 5'-CU and 5'-UU recognition elements are highlighted. The red arrow in $D$ indicates the absence of a purine at the site corresponding to A7-Trp-18 stacking in the $\lambda$ boxB-peptide complex. 
Fig. 6D). Although two purines are predicted in the loop, we speculate that in the absence of a specific GA-associated geometry a stable Trp-18-adenine interaction would not be possible. The $\phi 21 \mathrm{~N}$ protein also lacks a corresponding aromatic amino acid in its argininerich motif (Fig. 6A, line 3; Franklin 1985b). Whether P22 or $\phi 21 \mathrm{~N}$-boxB complexes define anal ogous N usA-RNAPbinding surfaces in the assembly of a processive antitermination complex is not known. Future comparison of these structures and anal ysis of their interactions within the elongation machinery promises to reveal both general principles and divergent strategi es of RN A-mediated transcriptional antitermination.

\section{Molecular mimicry underlies the design of a genetic} switch

The present study has focused on an RNA-based mechanism of transcriptional regulation in phage $\lambda . \mathrm{N}$-directed antitermination requires a specific network of interactions between the nascent message and host proteins, including RN AP and the N us elongation factors (M ason and Greenblatt 1991; Li et al. 1992, M ason et al. 1992; DeVito and Das 1994; M ogridge et al . 1995). The present dissection of one component of this network-induction of a novel boxB structure by an $\mathrm{N}$ peptide-demonstrates costabilization of a novel RNA structure. The distinct structural role of each base in the $\lambda$ boxB pentaloop rationalizes its genetic analysis (Salstrom and Szybalski 1978; Doelling and Franklin 1989; Chattopadhyay et al. 1995a). The active RNA structure recapitulates features of the classical GNRA tetraloop and provides a novel surface for recognition by N usA (Chattopadhyay et al. 1995a; M ogridge et al . 1995). An induced pattern of RNA base-pairing, -stacking, and -flipping thus mediates successive steps of RNA-protein assembly in transcriptional antitermination. The diverse structural repertoire of RNA underlies the design of a genetic switch.

\section{Materials and methods}

\section{RNA synthesis}

Oligonucleotides were prepared by solid-phase synthesis with $\beta$-cyanoethyl-phosphoramidite reagents (Davis 1995). For binding studies the crude product was purified from denaturing PAGE and desalted with Sephadex G-25. Preparative purification for spectroscopic study was accomplished using ion-exchange high-performance liquid chromatography (HPLC). Purity ( $>98 \%$ ) was assessed by HPLC and gel el ectrophoresis with ${ }^{32} \mathrm{P}$ autoradiography.

\section{Peptide synthesis}

Peptides were prepared by solid-phase synthesis using F moc chemistry and contain carboxy-terminal amide groups. Following deprotection and cleavage from the resin, the crude product was Iyophilized, desalted using Sephadex G-25 Superfine, and purified by reverse-phase HPLC. Fidelity of synthesis was verified by matrix-assisted laser desorption ionization time of flight (MALDI-TOF) mass spectrometry. Peptide concentration were measured by OD at 280 or $210 \mathrm{~nm}$. Purity ( $>98 \%$ ) was assessed by HPLC and mass spectrometry [Peptide numbers refer to the codon number including the initiator methionine (Franklin et al. 1985b); the amino-terminal residue of the peptide is hence designated Asp2, the second reisue Ala3, etc.].

GMSAS

Complexes were incubated at $4^{\circ} \mathrm{C}$ in $20 \mathrm{~mm}$ Tris-acetate and 50 $\mathrm{mm}$ potassium acetate at $\mathrm{pH} 7.9$ (as measured at room temperature). Free and bound species were resolved at $4^{\circ} \mathrm{C}$ using a $10 \%$ gel (20:1 acrylamide/bis-acrylamide) in $10 \mathrm{~mm}$ Tris-HCl, $9 \mathrm{~mm}$ boric acid, $0.1 \mathrm{~mm}$ EDTA (pH 7.3) (at room temperature). Dissociation constants of weak complexes were obtained by fluorescence (Van Gilst et al. 1997).

CD

CD spectra were obtained at $4^{\circ} \mathrm{C}$ using an A viv spectropolarimeter with a path length of $1 \mathrm{~mm}$. Binding buffer consisted of 10 $\mathrm{mm}$ potassium phosphate (pH 7.4), $100 \mathrm{mM} \mathrm{KCl}$ and $0.1 \mathrm{~mm}$ EDTA.

\section{Fluorescence spectroscopy}

Spectra were obtained using a SPEX steady-state fluorimeter with an excitation wavel ength of $295 \mathrm{~nm}$ to minimize the inner filter effect of peptide-RNA solutions. Correction of the inner filter effect was based on control experiments in $2 \mathrm{M} \mathrm{KCl}$ (Fig. $4 \mathrm{~A}$ ), in which no binding is presumed. Dissociation constants of weak complexes were estimated from the concentration-dependent quenching of an equimolar RNA-peptide solution (Van Gilst et al. 1997). A path length of $1 \mathrm{~cm}$ was used at a peptide concentration of $0.06-5 \mu \mathrm{m}$ at $4^{\circ} \mathrm{C}$. The buffers were as described for CD studies.

\section{NMR spectroscopy}

${ }^{1} \mathrm{H}-\mathrm{N}$ M R spectra were obtained at $400,500,600$, and $750 \mathrm{M} \mathrm{Hz}$. RNA resonance assignments using ${ }^{1} \mathrm{H}$ and natural abundance ${ }^{13} \mathrm{C}$ N M R methods were obtained as described (Verani and TinCOCo 1991). N OESY mixing times of $40,50,60,70,150,300$, and 500 msec were employed; TOCSY mixing times of 55,80 , and $110 \mathrm{msec}$ were employed. Direct N OEs were calibrated at low mixing times $\left(30-70 \mathrm{msec}\right.$ at $\left.25^{\circ} \mathrm{C}\right)$ in reference to standard distances constrained by coval ent structure (pyrimidine $\mathrm{H}_{5}-\mathrm{H}_{6}$ ); spin diffusion was assessed in reference to NOEs within the indole ring of Trp-18 $\left(\mathrm{H}_{4} \rightarrow \mathrm{H}_{5} \rightarrow \mathrm{H}_{6} \rightarrow \mathrm{H}_{7}\right)$. Spectra were obtained at $4^{\circ} \mathrm{C}$ and $25^{\circ} \mathrm{C}$. Resonance assignments in the pentaloop were obtained by comparison of spectra of the native, A7U and A8G complexes. NMR buffer consists of $10 \mathrm{~mm}$ sodium phosphate $(\mathrm{pH} \mathrm{6.0)}$ and $50 \mathrm{~mm} \mathrm{~N} \mathrm{aCl}$. Spectra at 400,500, and $600 \mathrm{MHz}$ were obtained at the Biological N MR Facility at The University of Chicago (IL); spectra at $750 \mathrm{M} \mathrm{Hz}$ were obtained at the $\mathrm{N}$ ational Institutes of Health $(\mathrm{NIH})$-supported N M R Facility at the University of Wisconsin at M adison (N M RFAM).

\section{Acknowledgments}

Wethank A. Das, N . Franklin, A. Jancso, P. Mueller, and S. Kron for discussion and advice on the manuscript; D. Jones for advice regarding N MR methods; and reviewers for insightful suggestions. This work was supported in part by a grant from the Council for Tobacco Research and $\mathrm{N}$ ational Institutes of Health (NIH) (M.A.W.) and the NIH Diabetes Research and Training 
Center at The University of Chicago (S.N., M.Z., and M.A.W.). H.C. is the recipient of a postdoctoral fellowship from Women's Board of the University of Chicago Cancer Research Center. M.A.W. is an Established Investigator of the American Heart Association, Lucille Markey Scholar, and Bane Scholar at The University of Chicago.

The publication costs of this article were defrayed in part by payment of page charges. This article must therefore be hereby marked "advertisement" in accordance with 18 USC section 1734 solely to indicate this fact.

\section{References}

Albrechtsen, B., C.L. Squires, S. Li, and C. Squires. 1990. Antitermination of characterized transcriptional terminators by the Escherichia coli rrnG leader sequence. J. Mol. Biol. 213: 123-134.

Antao, V.P., S.Y. Lai, and I. Tinoco, Jr. 1991. A thermodynamic study of unusually stable RNA and DNA hairpins. Nucleic Acids Res. 19: 5901-5905.

Barik, S., B. Ghosh, W. Whalen, D. Lazinski, and A. Das. 1987. $A n$ antitermination protein engages the elongating transcription apparatus at a promoter-proximal recognition site. Cell 50: 885-899.

Battiste, J.L., R. Tan, A.D. Frankel, and J.R. Williamson. 1994. Binding of an HIV Rev peptide to Rev responsive element RNA induces formation of purine-purine base pairs. Biochemistry 33: 2741-2747.

Battiste, J.L., H. Mao, N.S. Rao, R. Tan, D.R. M uhandiram, L.E. Kay, A.D. Frankel, and J.R. Williamson. 1996. Alpha helixRNA major groove recognition in an HIV-1 rev peptide-RRE RN A complex. Science 273: 1547-1551.

Cate, J.H., A.R. Gooding, E. Podell, K. Zhou, B.L. Golden, A.A. Szewczak, C.E. Kundrot, T.R. Cech, and J.A. Doudna. 1996. Crystal structure of a group I ribozyme domain: Principles of RN A packing. Science 273: 1678-1685.

Chattopadhyay, S., J. Garcia-M ena, J. DeVito, K. Wolska, and A. Das. 1995a. Bipartite function of a small RNA hairpin in transcription antitermination in bacteriophage lambda. Proc. Natl. Acad. Sci. 92: 4061-4065.

Chattopadhyay, S., S.C. Hung, A.C. Stuart, A.G. Palmer, III, J. Garcia-M ena, A. Das, and M.E. Gottesman. 1995b. Interaction between the phage HK022 N un protein and the nut RNA of phage lambda. Proc. Natl. Acad. Sci. 92: 1213112135.

Cilley, C.D. and J.R. Williamson. 1997. Analysis of bacteriophage $\mathrm{N}$ protein and peptide binding to boxB RNA using polyacrylamide gel coelectrophoresis (PACE). RNA 3: 57-67.

Das, A. 1993. Control of transcription termination by RNAbinding proteins. Annu. Rev. Biochem. 62: 893-930.

Davis, R.H. 1995. Large-scale oligoribonucleotide production. Curr. Opin. Biotechnol. 6: 213-217

de Crombrugghe, B., M. Mudryj, R. DiLauro, and M. Gottesman. 1979. Specificity of the bacteriophage lambda $N$ gene product $(\mathrm{pN})$ : nut sequences are necessary and sufficient for antitermination by $\mathrm{pN}$. Cell 18: 1145-1151.

DeVito, J. and A. Das. 1994. Control of transcription processivity in phage lambda: $\mathrm{N}$ us factors strengthen the terminationresistant state of RNA polymerase induced by $\mathrm{N}$ antiterminator. Proc. Natl. Acad. Sci. 91: 8660-8664.

Doelling, J.H. and N.C. Franklin. 1989. Effects of all single base substitutions in the loop of boxB on antitermination of transcription by bacteriophage lambda's $\mathrm{N}$ protein. Nucleic Acids Res. 17: 5565-5577.

Fan, P., A.K. Suri, R. Fiala, D. Live, and D.J. Patel. 1996. Mo- lecular recognition in the FMN-RNA aptamer complex. J. Mol. Biol. 258: 480-500.

Franklin, N.C. 1985a. Conservation of genome form but not sequence in the transcription antitermination determinants of bacteriophages lambda, $\phi 21$ and P22. J. Mol. Biol. 181: 7584.

- - . 1985b. "N" transcription antitermination proteins of bacteriophages lambda, $\phi 21$ and P22. J. Mol. Biol. 181: 8591.

- - 1993. Clustered arginine residues of bacteriophage lambda $\mathrm{N}$ protein are essential to antitermination of transcription, but their locale cannot compensate for boxB loop defects. J. Mol. Biol. 231: 343-360.

Friedman, D.I. and E.R. OIson. 1983. Evidence that a nucleotide sequence, "boxA", is involved in the action of the N usA protein. Cell 34: 143-149.

Greenblatt, J., J.R. N odwell, and S.W. M ason. 1993. Transcriptional antitermination. Nature 364: 401-406.

Harada, K., S.S. Martin, and A.D. Frankel. 1996. Selection of RN A-binding peptides in vivo. Nature 380: 175-179.

Henthorn, K.S. and D.I. Friedman. 1996. Identification of functional regions of the $\mathrm{N}$ un transcription termination protein of phage $\mathrm{HKO} 022$ and the $\mathrm{N}$ antitermination protein of phage gamma using hybrid nun-N genes. J. Mol. Biol. 257: 9-20.

Heus, H.A. and A. Pardi. 1991. Structural features that give rise to the unusual stability of RNA hairpins containing GNRA loops. Science 253: 191-194.

Hung, S.C. and M.E. Gottesman. 1995. Phage HK022 N un protein arrests transcription on phage lambda DN A in vitro and competes with the phage lambda $\mathrm{N}$ antitermination protein. J. Mol. Biol. 247: 428-442.

Jain, C. and J.G. Belasco. 1996. A structural model for the HIV-1 Rev-RRE complex deduced from altered-specificity Rev variants isolated by a rapid genetic strategy. Cell 87: $115-125$.

Jucker, F.M., H.A. Heus, P.F. Yip, E.H.M. Moors, and A. Pardi. 1996. A network of heterogeneous hydrogen bonds in GN RA tetral oops. J. Mol. Biol. 264: 968-980.

King, R.A., S. Banik-M atai, D.J. Jun, and R.A. Weisberg. 1996. Transcripts that increase the processivity and elongation rate of RNA polymerase. Cell 87: 893-903.

Lazinski D., E. Grzadzielska, and A. Das. 1989. Sequence-specific recognition of RNA hairpins by bacteriophage antiterminators requires a conserved arginine-rich motif. Cell 59: 207-218.

Li, J., R. Horwitz, S. M cCracken, and J. Greenblatt. 1992. N usG, a new Escherichia coli elongation factor involved in transcriptional antitermination by the $\mathrm{N}$ protein of phage lambda. J. Biol. Chem. 267: 6012-6019.

Li, S.C., C.L. Squires, and C. Squires. 1984. Antitermination of E. coli rRN A transcription is caused by a control region segment containing lambda nut-like sequences. Cell 38: 851860.

Mason, S.W. and J. Greenblatt. 1991. Assembly of transcription elongation complexes containing the $\mathrm{N}$ protein of phage $\lambda$ and the Escherichia coli elongation factors NusA, N usB, N usG, and S10. Genes \& Dev. 5: 1504-1512.

Mason, S.W., J. Li, and J. Greenblatt. 1992. Host factor requirements for processive antitermination of transcription and suppression of pausing by the $\mathrm{N}$ protein of bacteriophage Iambda. J. Biol. Chem. 267: 19418-19426.

Mogridge, J., T.F. Mah, and J. Greenblatt. 1995. A protein-RN A interaction network facilitates the template-independent cooperative assembly on RNA polymerase of a stable antitermination complex containing the $\lambda \mathrm{N}$ protein. Genes $\&$ Dev. 9: 2831-2845. 
Morgan, E.A. 1986. Antitermination mechanisms in rRNA operons in Escherichia coli. J. Bacteriol. 168: 1-5.

N odwell, J.R. and J. Greenblatt. 1991. The nut site of bacteriophage lambda is made of RN A and is bound by transcription antitermination factors on the surface of RNA polymerase. Genes \& Dev. 5: 2141-2151.

- - 1993. Recognition of boxA antiterminator RNA by the E. coli antitermination factors N usB and ribosomal protein S10. Cell 72: 261-268.

Olson, E.R., E.L. Flamm, and D.I. Friedman. 1982. Analysis of nut $_{R}$ : $A$ region of phage lambda required for antitermination of transcription. Cell 31: 61-70.

Olson, E.R., C.S. Tomich, and D.I. Friedman. 1984. The nusA recognition site. Alteration in its sequence or position relative to upstream translation interferes with the action of the $\mathrm{N}$ antitermination function of phage lambda. J. Mol. Biol. 180: 1053-1063.

Orita, M., F. Nishikawa, T. Shimayama, K. Taira, Y. Endo, and S. Nishikawa. 1993. High-resolution NMR study of a synthetic oligoribonucleotide with a tetranucleotide GAGA loop that is a substrate for the cytotoxic protein, ricin. Nucleic Acids Res. 21: 5670-5678.

Patterson, T .A., Z. Zhang, T. Baker, L.L. Johnson, D.I. Friedman, and D.L. Court. 1994. Bacteriophage Iambda N-dependent transcription antitermination. Competition for an RNA site may regulate antitermination. J. Mol. Biol. 236: 217-228.

Pley, H.W., K.M. Flaherty, and D.B. McKay. 1994a. Three-dimensional structure of a hammerhead ribozyme. Nature 372: 68-74.

- - . 1994b. Model for an RN A tertiary interaction from the structure of intermolecular complex between a GAAA tetral oop and an RNA helix. Nature 372: 111-113.

Puglisi, J.D., L. Chen, A.D. Frankel, and J.R. Williamsons. 1993. Role of RN A structure in arginine recognition of TAR RNA. Proc. Natl. Acad. Sci. 90: 3680-3684.

Puglisi, J.D., L. Chen, S. Blanchard, and A.D. Frankel. 1995. Solution Structure of a bovine immunodeficiency virus Tat peptide-TAR RN A complex. Science 270: 1200-1203.

Rees, W.A., S.E. Weitzel, T.D. Yager, A. Das, and P.H. von Hippel. 1996. Bacteriophage lambda $\mathrm{N}$ protein al one can induce transcription antitermination in vitro. Proc. Natl. Acad. Sci. 93: 342-346.

Roberts, J.W. 1969. Termination factor for RN A synthesis. Nature 224: 1168-1174.

Roberts, R.J. 1995. On base flipping. Cell 82: 9-12.

Salstrom, J.S. and W. Szybalski. 1978. Coliphage $\lambda$ nutL'- A unique class of mutants defective in the site of gene $\mathrm{N}$ product utilization for antitermination of leftward transcription. J. Mol. Biol. 124: 195-221.

Schauer, A.T., D.L. Carver, B. Bigelow, L.S. Baron, and D.I. Friedman. 1987. Lambda $\mathrm{N}$ antitermination system: Functional analysis of phage interactions with the host NusA protein. J. Mol. Biol. 194: 679-690.

Su, L., J. Radek, K. Hallenga, P. Hermanto, and M.A. Weiss. 1997. A bent $\alpha$-helix regulates transcirptional antitermination in phage $\lambda$. Biochemistry (in press).

Tan, R. and A.D. Frankel. 1994. Costabilization of peptide and RNA structure in an HIV Rev peptide-RRE complex. Biochemistry 33: 14579-14585.

- - - 1995. Structural variety of arginine-rich RNA-binding peptides. Proc. Natl. Acad. Sci. 92: 5282-5286.

Tan, R., L. Chen, J.A. Buettner, D. Hudson, and A.D. Frankel. 1993. RNA recognition by an isolated alpha helix. Cell 73: 1031-1040.

Van Gilst, M., W.A. Rees, A. Das, and P.H. von Hippel. 1997. Complexes of $\mathrm{N}$ Antitermination Protein of phage $\lambda$ with specific and nonspecific RNA target sites on the nascent transcript. Biochemistry 36:1514-1524.

Varani, G. and I. Tinoco, Jr. 1991. RNA structure and NMR spectroscopy. Q. Rev. Biophys. 24: 479-532.

Warren, F. and A. Das. 1984. Formation of termination-resistant transcription complex at phage lambda nut locus: Effects of altered translation and a ribosomal mutation. Proc. Natl. Acad. Sci. 81: 3612-3616.

Whalen, W.A. and A. Das. 1990. Action of an RNA site at a distance: Role of the nut genetic signal in transcription antitermination by phage-lambda $\mathrm{N}$ gene product. New Biol. 2: 975-991.

Whalen, W., B. Ghosh, and A. Das. 1988. N usA protein is necessary and sufficient in vitro for phage lambda $\mathrm{N}$ gene product to suppress a rho-independent terminator placed downstream of nut ${ }_{L}$. Proc. Natl. Acad. Sci. 85: 2494-2498.

Wimberly, B. 1994. A common RNA loop motif as a docking module and its function in the hammerhead ribozyme. Nature Struct. Biol. 1: 820-827.

Ye, X., R.A. Kumar, and D.J. Patel. 1995. M olecular Recognition in the bovine immunodeficiency virus Tat peptide-TAR RN A complex. Chem. Biol. 2: 827-840.

Ye, X., A. Gorin, A.D. Ellington, and D.J. Patel. 1996. Deep penetration of an alpha-helix into a widened RNA major groove in the HIV-1 rev peptide-RN A aptamer complex. Nature Struct. Biol. 3:1026-1033.

Zuber, M., T.A. Patterson, and D.L. Court. 1987. Analysis of nutR, a site required for transcription antitermination in phage lambda. Proc. Natl. Acad. Sci. 84: 4514-4518. 


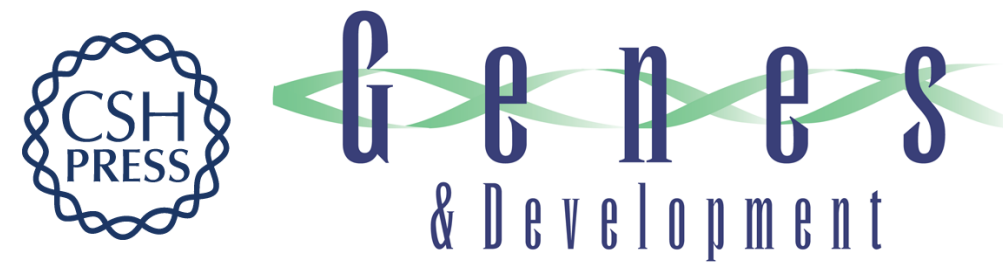

\section{An RNA enhancer in a phage transcriptional antitermination complex functions as a structural switch}

Leila Su, James T. Radek, Laura A. Labeots, et al.

Genes Dev. 1997, 11:

Access the most recent version at doi:10.1101/gad.11.17.2214

References This article cites 61 articles, 20 of which can be accessed free at: http://genesdev.cshlp.org/content/11/17/2214.full.html\#ref-list-1

License

Email Alerting

Receive free email alerts when new articles cite this article - sign up in the box at the top Service right corner of the article or click here.

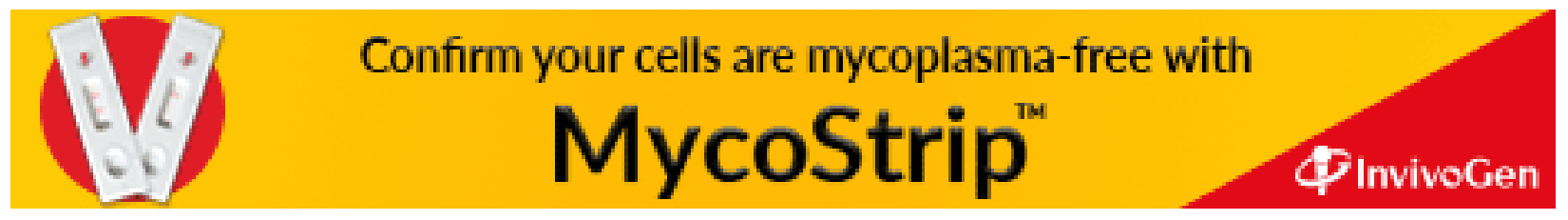

